\title{
EL PUNTO DE PARTIDA DE LA ONTOLOGÍA UTÓPICA DE ERNST BLOCH
}

\author{
Luis F. Aguilar Villanueva
}

Facultad de Ciencias políticas y sociales Universidad Nacional Autónoma de MÉxico

1. El "Admirarse" [Staunen] como inauguración de la filosofia o surgimiento de la cuestión ontológica

Para Bloch, el punto de partida filosófico es el revelarse del ser como mera pregunta sin respuesta conclusiva, como oscuridad; tiene su origen en el acto de admirarse, en "la admiración cuestionadora" [das Staunen, das fragende Staunen]. La experiencia de la admiración impide que el ejercicio filosófico comience desde un punto de vista subjetivo, o con una pregunta construida desde acríticos intereses privados o sociales, y logra que la filosofía arranque a partir de la misma realidad que se presenta como posición problemática o planteo, en la medida que la realidad puesta se declara ahora sin respuesta, mera pregunta acerca de sí misma.

El pensamiento nace de una necesidad concreta por resolver: "la necesidad enseña a pensar" [Not lehrt denken]. A causa de nuestra existencial indigencia, el pensamiento se pone en marcha y por medio de un trabajo crítico y proyectual se esfuerza por disminuir las necesidades de la vida. Para esto el hombre se sirve inicialmente del contorno natural y social que está a su disposición. Sin embargo, el pensamiento, inconfundiblemente humano, quiere y "puede, después que la necesidad lo ha despertado, volverse profundo", quiere entender desde la raíz el por qué de su tan universal y penosa indigencia y el por qué de la insuficiencia y precariedad de su contorno de existencia; quiere pensar el profundo fundamento "responsable" de tal situación de existencia, el que respondería exhaustivamente a la pregunta. Por esto, apenas satisface el hombre sus necesidades vitales, y hasta en el mismo proceso de búsqueda de la satisfacción, viene a luz y "continúa en vida una búsqueda más profunda que nos arrastra consigo; esto es, el Maravillarse, el Admirarse"."

1 Tübinger Einleitung in die Philosophie, Suhrkamp Verlag, Frankfurt, 1963, p. 15. 
En la infancia, muy comúnmente, suceden ciertos hechos o ciertas realidades que nos impresionan e interrogan, sacudiendo nuestro universo de evidencias. En la edad adulta suceden más raramente, pero son más aleccionadores. Estos sucesos son rápidas y leves impresiones del sujeto, ocasionadas casi siempre por objetos de poca apariencia, que forman parte de nucstro mundo rutinario de cxpcricncia, por cjemplo, cl ramo de un abeto, la lluvia, el mar, un paisaje cubierto de nieve, la yerba o una brizna solitaria, un sábado o. domingo por la tarde (todas expresiones de Bloch). Sin embargo, estos sucesos, que surgen de repente e inesperadamente, rompen el ritmo cotidiano y el contorno habitual de nuestra existencia y experiencia. Se nos paran delante, de pronto, como algo nuevo y extraordinario y nos revelan últimamente un aspecto y un significado inusitado y sorprendente que provoca dentro de nosotros una admiración, quizás entusiasta o quizás deprimente, pero ya no superficial o particular, sino profunda y universal. Son impresiones ocasionales, imprevistas y, sin embargo, son igualmente la ocasión para que la existencia y su mundo se coloquen improvisadamente dentro de un horizonte que ya no se revela ocasional sino fundamental y se depositen en la profundidad de un misterio impresionante. En ese instante repentino, los objetos de nuestra cotidiana circunstancia no se presentan ya como algo obvio, ya demasiado usados y consumados por el lenguaje, el pensamiento y la acción, o como algo siempre puesto fácilmente a nuestra disposición y en función de nuestras necesidades. No nos interesa, además, nombrarlos, comprenderlos, poseerlos y maniobrarlos en esa su dimensión fácilmente accesible. En ese instante los objetos se transforman y nos muestran un aspecto nuevo, radiante o tenebroso. Y la novedad, tan rara, de su aspecto desacostumbrado los convierte en algo oscuro y problemático para el lenguaje, el pensamiento y la práctica.

No obstante esto, su novedad y oscuridad problemática nos cautiva, nos importa y nos interesa por sobre todas las cosas, pues a partir de la experiencia de la admiración los objetos abandonan su gastada obviedad y rutina y se remiten a "algo" que parece ser lo más fundamental e importante, que parece permear y animar todas las cosas. A partir de la admiración todo el contorno de nuestra existencia se revela con una calidad nueva, diversa, desconocida y, por tanto, se transforma en algo enigmático, colocado dentro de signos interrogativos, como un problema digno de afrontar y de resolver. Nuestra admiración ante esta nueva dimensión de la cosa, que era una dimensión desconocida e insospechable antes de la maravilla, es así una admiración-problema. La admiración, ocasionada tan banalmente, nos obliga a entrar en una región inusitada, inexplorada, extraordinaria, y nos obliga a encararnos con 
lo que se ha vuelto de pronto incomprensible, inefable, indisponible, sin un rostro identificable. Una región que parece ser la más importante, la portante, si bien la más difícil para el saber y para el nombrar. La más decisiva y la más concerniente para la existencia, pues el destino de la existencia aparece de pronto inundado, arrastrado y normado por ese "algo". La admiración, pues, incluye espontáneamente una pregunta acerca de ese "algo" nuevo, raro y extraño (pero, ¿es "algo"? ¿O nombrarlo "algo" es ya un intento irresponsable de reducir a lo notorio, a lo disponible y superficial?). Por la mediación de la admiración ante esta nueva dimensión del mundo, el preguntar humano corta y rompe su relación con las cosas-fenómenos que constituyen el cuadro cotidiano de sus pensamientos e intereses; cesa de entenderlas y nombrarlas a partir de su mera funcionalidad o disfuncionalidad y desplaza su cuestión hacia esa nueva y más profunda dimensión que se ha abierto instantáneamente por dentro de la vieja y usual dimensión de las cosas circunstantes. La nueva dimensión abierta por el maravillarse (ora como la rendija luminosa por la que se ve un horizonte sublime y positivo, ora como el asomarse con horror a un abismo de la sima negativa y vacia) es $E l s e r$, el que las cosas son [das Dass-Sein] y la pregunta asociada al maravillarse vierte sobre el Ser mismo, sobre el lo que del que las cosas son [das Was-Sein], sobre el sentido y la calidad propia del Ser.

El maravillarse es, pues, la experiencia ontológica que nos sorprende y asombra por ser tan diversa de la experiencia óntica, por ser tan indefinida, fugaz, y a la par tan omnicomprensiva y universal. Efectivamente, en la admiración interrogativa no nos maravillamos directa o especialmente de algo, de algo que nos está ahí delante y ante los ojos, ni siquiera de un algo que de repente se vuelve extraño por ser bizarro, sorpresivo, exagerado, descompuesto... y así nos llama la atención. Nuestro instantáneo asombro (admiración o estupor) delante de un objeto, que como objeto es ya demasiado notorio hasta el aburrimiento, abre dentro del objeto una profundidad ignota y desacostumbrada y desciende por esta apertura hasta tocar eso que ya no aparece como objeto, sino que es el mismo ser del objeto y, por consiguiente, el ser de cada objeto, el ser mismo. $O$ con otras palabras, nuestra admiración se refiere limpiamente al Eso que todo nuestro contorno natural-social con la variedad de sus formas es, al ser mismo. Con el maravillarse surge lo ontológico, revelándose y escondiéndose, abriéndose y cerrándose, y surge por dentro de nuestras preguntas y respuestas ónticas. Nuestra admiración es acicateada directa y principalmente por el descubrimiento del ser del ente, del que se es en su pureza original y originante. Este original descubrimiento trae consigo una inquietante pregunta que no sólo rebasa todas nuestras habituales preguntas-respuestas, sino que las pone pro- 
fundamente en crisis, pues todas nuestras respuestas anteriores, además de ser inútiles y no concernientes para el nivel de esta dimensión profunda y $\tan$ nueva, se vuelven a su vez problemas que no hacen sino reproponer y modular esta pregunta radical y cuyo preguntarse sobre sí es ya un preguntarse sobre la posibilidad y la validez de su preguntarse. En efecto, aquí todo es tan diverso, tan inusitado y tan ignoto, que la pregunta misma construida con los nombres y conceptos de la vieja dimensión parece no ser atingente y sí sospechosa. Porque se es, ¿qué es el que se es? ¿Por qué y para qué se es? ¿Por qué el Ser y qué es el Ser? ¿Por qué el Ser y no la nada? ¿Por qué el devenir y no el ser? Y a esta pregunta, que parece ser la más lejana y es en cambio la que nos toca más de cerca, la más abstracta y es la más concreta, toda pregunta se remite y de ella toda pregunta nace: "la semilla de toda cuestión" [der Keim alles Fragens].

"Este maravillarse no es ya un maravillarse acerca de algo, sino maravillarse de que se es [Dass] y de su correspondiente lo-que [Was], tan lleno en su interior de otros muchos algos [Etwas]." " En la admiración, ya sea maravilla o espanto, el ser y su interioridad vienen evocados, y vienen evocados como algo misterioso y problemático, pues su presentarse y la calidad con la cual se presentan no son reducibles y asimilables a la obvia presencia y a la calidad manifiesta que los objetos de nuestra circunstancia mundana hoy tienen. No se encuentran ideas y palabras que puedan expresar adecuadamente "lo que las palabras preguntando parecen decir y lo que diciendo parecen preguntar", lo que ocultando revelan y revelando ocultan, en el momento que intentaron reproducir y traducir la experiencia ontológica del "maravillarse". El problema se radicaliza más aún, cuando no sólo se trata de aprehender ( $y$ de aprender a aprehender, que es un difícil aprendizaje) puramente la originalidad de la presencia del ser, sino cuando se trata de comprender su calidad, su contenido y significado, la "esencia" del ser. Es, entonces, cuando su oscuridad es más densa y el problema aumenta el número de sus incógnitas, en razón de la irreductibilidad del ser al ente (que fue el primer resultado y descubrimiento de la admiración), en razón de su no ser definido y su estar plenamente determinado en la determinación de sus fenómenos, que son y no son, que son así y no son así.

El ser, entonces, aparece como una calidad difusa, invisible e impalpable, por todas partes y en ninguna de ellas, ahora y no ahora, aquí y ahí y no aquí ni ahí. Por esto mismo, el ser aparece como vacío y contradictorio consigo mismo. $\mathrm{O}$ bien, en razón de su vacuidad y auto- 
contradicción, como lo todavía posiblemente abierto a determinaciones nuevas y diversas. La dimensión ontológica parece, pues, estar suspendida "en vilo sobre la nada". Y la nada aparece como el lugar donde el ser siempre habita, el lugar donde el ser es siempre no ser: la admiración y la nada como pavor ante un ser sin substancia, ante el Fracaso ontológico. O bien, la nada aparece como el lugar en que el ser, en razón de su negatividad, podría no ser como aquí y ahora es: la admiración y el Todo como esperanza-utopía de Éxito ontológico. Es decir, en el contenido original y enigmático de la admiración hay lugar para el malestar y el desconcierto originados por la actual negatividad, oscuridad, oquedad del ser, al no darse como puro ser en el mundo y en la historia, así como para la esperanza, ontologicamente fundamentada en esa misma negatividad y vacuidad, que se refiere a "otro" ser, en el que la admiración ante el ser no sea ya oscuro misterio y problema, sino pura estupenda y arrebatadora "admiración en sí misma" [Selberstaunen]: el ser como diáfano y óptimo e idéntico consigo mismo, el ser como respuesta revelada y hermosa "autosolución".

De todos modos, esta bifacialidad de la admiración ontológica declara ya la incapacidad de comprender aquí y ahora, de manera nítida, la "esencia" del ser; declara ya sin claridad que el ser responde a nuestra pregunta planteándose como pregunta y que el ser en su revelarse se nos oculta. Lo que inaugura, en suma, la ontología es la admiraciónproblema-misterio de ser y de ser como "No-Ser-Ahi" [Nicht-Da-Sein], que es simultáneamente el nacimiento del filosofar, el planteo del problema ontológico y la indicación de la ruta del método "responsable". En conclusión, en la admiración, ocasionada por un hecho superficial y pobre de contenido, tiene lugar la radical y riquísima cuestión que toca la profundidad fundamental de todo el universo.

Cuestión que no se refiere a algo ya existente y constituido, sino que concierne a lo que es en sí un problema que marcha por el mundo sin haberse concluido y resuelto. Aquí (en la admiración) resuena el problema fundamental del existir, cuya respuesta se logra sólo con el existir mismo y con sus mismos materiales aún irrealizados. ${ }^{3}$

Sí, piense usted sólo en esto: Ilueve. Quien vivió esto, se sintió de repente capturado por la admiración, retrocedió hasta lo que está más atrás y se adelantó hasta lo que está más adelante. En verdad, fue una pequeña cosa lo que ocasionó su admiración y, sin embargo, fue ella la que de pronto lo condujo a la semilla de toda

3 Ibid., p. 19. 
pregunta. Nuestros estados de ánimo juveniles son frecuentemente más vacíos y puros: nos asomamos a la ventana, salimos a caminar por la calle, nos detenemos, dormimos, nos despertamos... y todo es siempre tan igual, nos parece vivir siempre con el mismo sentimiento oscuro: qqué inquietante es todo y qué tremendamente extraño es "ser"! En realidad, esta expresión es ya bastante exagerada, como si sólo el ser fuera lo misterioso, pues no sería menos enigmático pensar que no existiera nada. No se encuentran las palabras capaces de expresar adecuadamente todo esto. $Y$, si se encuentran, se violenta la admiración original. ${ }^{4}$

¿No está el hombre con su "ser" en vilo sobre la nada? La nada en la que él simplemente ya no existiría o bien en la que ya no sería así como aquí y ahora es. ¿Y esta situación no convierte al hombre en algo doblemente extraño? ¿Acaso la pregunta de la pura admiración no va a terminar en esta "Nada" en la que ella espera encontrar su "Todo"? Por ende, el impacto de ver cuán inseguro y oscuro es el fundamento del mundo y, precisamente por esto, la esperanza de que todo pueda "ser" diverso, de que todo pueda llegar a ser nuestro "ser" más propio. La esperanza de que ya no sea necesaria pregunta alguna, sino que la pregunta se transforme totalmente en admiración y, por fin, en "felicidad": un ser como felicidad. ${ }^{5}$

La necesidad enseña a pensar, pues de ella nace la preocupación. Aunque se renueva sin cesar la presión de la preocupación, con ella se acompaña otro estímulo que le es afín. Este estímulo puede ser igualmente doloroso, pues parece que casi todo lo que nos hemos procurado o lo que aún no hemos logrado se inscribe dentro de una total impureza. Por esto, surge aquí el asombro, una admiración cuestionadora y su acicate. La admiración procede también de la misma necesidad, aunque ésta no sea ya tan inmediata, y se expresa en ese estado de ánimo que, debido a la impresión que se tiene de las cosas y a causa de las mismas cosas, nos hace sentir como si aún no hubiéramos llegado a casa, como si aún fuésemos extranjeros. La fuerza de este sentimiento aparece con todo su frescor en los niños, en las preguntas con las que expresan su admiración... Más aún, alrededor de los dieciséis o diecisiete años, de vez en cuando, aparece una admiración particularmente molesta e inquietante, que pregunta y quisiera saber: ¿por qué, en suma, existe algo y no la nada? Surge así la admiración, levanta su cabeza y expulsa la aceptación irreflexiva de los datos rutinarios. Y, enseguida, tal asombro, en la medida que se sirve de la razón y así

4 Spuren, Suhrkamp Verlag, Frankfurt, 1964, p. 284 s.

5 Ibid., p. 285 s. 
refuerza su independencia, destruye también ese encanto de las costumbres tradicionales y, sobre todo, de los conceptos supersticiosos. Con la admiración apareció en el pensamiento griego, a partir de Tales, la primera y pura luz de la filosofía. Los griegos nunca olvidaron en su filosofía la admiración y conjugaron, tanto a nivel de método como de contenido teórico, la pregunta propia de la admiración, esa pregunta que socialmente ha sido siempre impedida, pero también renovada. Pero, a pesar de todo, este primigenio impulso ha sido siempre el acicate. Donde él no existe, significa que no hay pensamiento fundamental $y$, tanto menos, profundo. ${ }^{\mathrm{s}}$

2. "La oscuridad del momento vivido" (Dunkel des gelebten Augenblicks) como la toma de conciencia de la pregunta ontológica y la indicación del método de respuesta

El pensar humano, cautivado por la fundamentalidad de la angustia o de la esperanza abierta en "el objeto" de la admiración, quiere introducirse por esa apertura para tratar de iluminar y traer a la luz ese oscuro enigma que se ha vuelto el centro de atracción de su pensamiento, de su lenguaje y de su práctica: el Ser. Por esto, la pregunta ontológica contenida en el maravillarse es a la vez la pregunta ineludible y la más importante para la conciencia y existencia humana, la cual advierte lucidamente que todas sus angustias y esperanzas (la maldad o bondad de existir), que son sus problemas y respuestas, se remiten ineludiblemente al ser como a su centro y fundamento, a lo que es y puede ser el ser, a lo que de él puede esperarse y lo que con él puede hacerse. En la admiración se captó la concentración de la Existencia en el Ser y se sintió agudamente la no importancia de saber, nombrar y poseer todo lo que aparece y existe en superficie, si no se sabe, ni se posee, ni se nombra esa profundidad que hace aparecer y existir, y que en cuanto profundidad está escondida al ojo empírico. En efecto, la admiración no plantea un problema acerca de "algo" que sólo relativamente nos concierne, en cuanto mantenemos de hecho una relación de necesidad con el afuera de los entes circundantes. El problema planteado por la admiración se vierte, en cambio, sobre aquello que nos concierne fundamentalmente y de lo cual no podemos prescindir nunca, pues incluye dentro de sí tanto al objeto exterior como a lo más adentro de nosotros mismos. Es por esto que el maravillarse no nos deja encargada una pregunta entre otras preguntas, sino la pregunta acerca de esa incógnita

B Philosophische Aufsätze, Suhrkamp Verlag, Frankfurt, 1969, p. 395 s. 
que nos carga a nosotros mismos, por la que somos y la que nosotros somos realmente.

Por tanto, el pensar ontológico, originado dentro del maravillarse, no puede no comenzar y comenzar por responder acerca de (y ser responsable de) ese fundamento problemático de todos los problemas del ente. Rehuír esta pregunta o comenzar con otro planteo diverso es infiel al contenido de la admiración y de su pregunta profunda. El problema, pues, es por dónde o desde dónde comenzar con fidelidad la profundización y la explicitación ontológica. Para intentar una comprensión del Ser, que corresponda adecuadamente al contenido de la maravilla, es decir, al que se es, no tenemos ningún otro posible punto de partida originario y más cercano que el Ahora [das Jetzt] de nuestro existir, el Que [das Dass] en este momento se es o somos, ya que sólo en el aquí y ahora es donde-cuando somos y donde-cuando todo está inscrito en el ámbito del ser. Como contraprueba, el punto de partida no puede ser el pasado, que ya no es y así ya no puede ser originalmente conocido, ni el futuro que es punto de llegada y, como tal, punto por venir al ser y a ser conocido.

Por lo dèmás, si para resolver el problema radical hay que remitir causalmente el Aquí y Ahora a un antecedente Allí y Entonces o a "otro" Ahí y Ahora contemporáneo, esto no es más que replantear la misma cuestión irresuelta y recaer en la vieja dimensión óntica, sin llegar a lo ontológico que es lo relevante y revelante filosóficamente y que fue la nueva dimensión abierta por la admiración. Cualquier recorrido metodológico en la dimensión de lo ya dado y puesto carece de significado para el pensamiento fundamental del origen y del contenido del origen. Ni importa aquí la dirección del recorrido, pues aquí se trata precisamente de aprehender el origen y comprender el significado de la dimensión fundamental que posibilita posteriormente el recorrido. El momento ontológico surge sólo cuando se cuestiona sobre la calidad esencial del fundamento del Ser-Ahora del ente, en cualquier punto donde acontezca el Ahora, basta que sea Ahora. Desde el punto de vista ontológico, ni el espacio ni el tiempo cambian la posición y el planteo del problema del origen del espacio y del tiempo. Más aún, sólo el Ahora es la posición del problema, porque sólo en el Ahora está a la obra el origen en su originalidad y originariedad y está, no como solución, sino como problema.

Bloch es explícito en este punto:

Fundus, lo fundamental en sentido absoluto, pensar partiendo desde el fundamento es parte de la filosfía y constituye lo que verdaderamente debe meditarse en ella... Sin embargo, para la refle- 
xión y la meditación que se ocupa de ese oscuro origen real, el Arqué no es arcaico sino presente. El legítimo deseo de tomar conciencia del fundamento, del primum agens del origen, encuentra su fundus más cerca en el Ahora que no en la afirmación de sucesos legendarios [Sagen als Saga]. Su dónde y su de dónde puede ser sólo atisbado en el hacia dónde y para qué. Por esto, no se puede evocar el fundamento sin pensar en el Ahora y sin acordarse últimamente de un Ser con Fundamento que preluce en la profundidad del tiempo, con un Fundamento que puede ser realizado perfectamente y que puede obtener su significado.?

¿Cómo se comienza? El pensar debe comenzar por alguna parte. El dónde del comienzo ha sido cambiante. Algunas veces estuvo en el centro, enteramente terminado de la cabeza a los pies. Sin embargo, un pensamiento, que quiere ir lejos y en el que se desarrolla algo, es en su comenzar pequeño $y$, al menos aparentemente, poca cosa. Aquello con lo cual se comienza, no está necesariamente impedido en su crecimiento. Sólo desde abajo se comienza. ¿Es mejor si se comienza de cerca? Ciertamente - Sin embargo, ¿Cuándo es que nosotros vivimos? En el Ahora, se responde... ${ }^{8}$

Bloch comienza en el Ahora. Sin embargo, este punto de partida, de por sí indiscutible y seguro, de por sí cercano e inmediato, no es de fácil acceso, ni está patentemente abierto. Nuestro primer encuentro con él es ya un encontrarnos antecedentemente dentro de él. Y nuestro querer comprenderlo es el estar ya comprendidos en él y por él. Esta cercanía o inmediatez del Ser-Ahora o, desde otro punto de vista, este nuestro estar ya incluidos precedentemente en el Ahora del ser, dificulta el comienzo, pues anula la distancia requerida para la claridad y perspicacia del examen del conocimiento, al no estar ahí delante como un objeto. Pero es así que el comienzo, gracias a la dificultad, se purifica y se constituye correctamente. Por consiguiente, el punto de partida, en lugar de ser la solución embrional, es la más radical toma de conciencia del problema ontológico en su concreta y real formulación y no como una cuestión construida ideológicamente por el filósofo. Es decir, el Ahora del ser es en sí mismo un "punto ciego", es oscuro. El ser aquí y ahora no es perceptible como lo es el ente. Nuestra primera confrontación con el ser no es la luz del ser que resplandece en el entendimiento (identidad entre Esse - Verum), sino la oscuridad, "la oscuridad del momento en que se es": un "logos" que no puede ser comprendido y nombrado. El revelarse del ser es su estar escondido y oscuro [Non-

7 Tübinger Einleitung in die Philosophie, p. 215.

8 lbid., p. 210. 
Esse, Non-Verum]. Comenzar, entonces, es el descubrimiento de algo no y aún no descubierto, del ser como "incógnita, $\mathrm{X}$, acertijo, misterio, problema en si" (expresiones de Bloch). Así el Ahora, que quizás pretendía responder a una cuestión proyectada o construida por nuestra razón inquisitoria, es en realidad la cuestión misma, la realidad como cuestión en sí y para sí. El Ahora del Ser, punto de partida para su tematización, es en sí y para sí el problema no construido ni "construible" [die unkonstruierbare Frage].

El análisis del Ahora nos llevará a conclusiones que cambian el acostumbrado modo de comenzar y de proceder filosóficamente. El primer resultado es que el Ahora es sobre todo "lo que permanece totalmente oscuro". "Que se es o se vive, esto no se puede percibir." "El Qué y Ahora, el instante en que somos, está envuelto en sí mismo y no se percibe." Éste es el tema inicial de la ontología blochiana, repetido incesantemente a lo largo de todas sus obras, como un leitmotiv. De aquí nace la opción filosófica de Bloch y aquí su posición tiene su fundamento.

Con la expresión "que se es o se vive aquí y ahora", Bloch entiende el ser en su sentido ontológico más puro, con su doble dimensión de ser del ente y de existencia del ente, de real acontecimiento o constitución del ente por el ser y de factualidad o existencia del ente, como resultado de su constitución. Ser es "eso por lo que se es" y "eso que se es y no se es nada", ni más ni menos. Bloch dirá siempre "El-Que se $e s^{\prime \prime}$ [das Dass-Sein]. Se trata de esa presencia real del ente, que, en cuanto presencia, es idéntica consigo misma: "es". $Y$ de ésa su presencia instantánea-simultánea, que la expresión "que se es ahora" recoge con precisión, de manera que "el Ahora" debe ser considerado estrictamente en la puntualidad e inmovilidad de su recogimiento, radicalmente diversa del despliegue y de la sucesión del devenir-tiempo. La admiración de Bloch tiene el sonido clásico del "Taumázein", así como el ser, que es el "objeto" de la admiración, tiene igualmente el sentido clásico (evitada toda substancialización y trascendencia del ser) de "esse" o "quo ens est".

En efecto, el ser nos maravilló e interrogó, porque no era reconducible a la obvia y habitual dimensión del ente o de lo-que es aquí y ahora, de lo puesto ante el conocimiento y al alcance del concepto, de la palabra y de la práctica funcional. Lo que nos maravilló no fue, en rigor, un "Lo-Que", sino "El-Que" un lo-que sea, el que los entes sean."

9 En Bloch, adelantando los resultados de su ontología, el ser no se reduce a ser sólo el ente, el contenido existente o la existencia de un contenido, su simple posición fuera del estado de posibilidad y de la nada, "actus vel factum essentiae". La filosofía de Bloch es, más bien, una crítica a toda comprensión esencialista o subs- 
Ahora bien, "El Que el ente es Ahora" es un acontecimiento gnoseológicamente oscuro que no comporta la manifestación directa del original y fundamental "Que" del ente y, por esto, oculta el qué sea y para$q u e ́$ sea el ser del ente. El Ser y, por consiguiente, la razón y sentido del ser, no se ponen de relieve en el Ahora del ente y tanto menos en el ente acontecido. El acontecimiento sucedido y manifiesto del $O n$ por el ser está sin una manifestación del Logos. La presencia real de lo óntico está sin un cuadro de referencia ontológica clara y distintamente revelada. Por esto, el Logos está ignoto, yace incomprendido, inexpresado, anónimo. La existencia manifiesta impide la manifestación del ser. Toda lectura intuitiva interpretativa del ser está bloqueada desde su comienzo por la presencia objetiva del ente y por la no objetividad del momento de su acontecimiento. Toda lectura del ser, al pasar por la mediación del ente, es ahora imposible inmediatamente. En el instante originario, donde-cuando acontece la actualidad del ente, no aparece ni el factor del acontecimiento y ni siquiera el acontecer del mismo acontecimiento. El ser es en el ente la oscuridad de sí y es ignoto e incognoscible en la medida que cae dentro del aquí y ahora. Si nuestro originario acontecimiento y su raiz caen necesariamente en el momento que se es o se vive, entonces éste y aquélla son totalmente oscuros.

De esta oscuridad del Ser original y originario del ente, Bloch habla primeramente en términos onticos-psicológicos (quoad nos), asentando el hecho y aduciendo las razones psíquicas y gnoseológicas de la oscuri-

tancialista del ser, sin caer, por eso, en el otro extremo de una mera concepción existencialista del ser, aunque el hecho de afirmar continuamente la no-esencia del ser del ente pueda sugerirlo. En efecto, el existencialismo está superado por Bloch en el mismo momento que él habla de un fundamento (el ser) de la existencia del ente y lo entiende como El Que es del ente y no como lo que es ente: El Ser es No-Ente. Y el esencialismo está superado en el momento en que Bloch afirma que el fundamento es el mero Que y no un Lo-Que puro: El Ser es No-Esencia. "Que se es" significa actualización y actualidad del ente por el ser y éste es entendido como Origen [Ursprung] y no como un Contenido [Inhalt] que en tanto pone el ente, en cuanto se concretiza y materializa en la existencia del ente. Bloch expresa sintética y abstractamente el Ser-Fundamento con un concepto quizás difícil para el lenguaje y para el espontáneo modo de pensar español: "das Dass", "El Que". O bien lo llama "der Wer", "El Quien". Y al definirlos en contraposición al "das Was", "Lo Que", Bloch entiende afirmar claramente que el ser del ente no es el mero hecho de ser del ente (lo-que-es ahí) ni la absoluta esencia lógica ya terminada y concluida que se revela en el ente como en su fenómeno. De todos modos, adelantando aquí los resultados de la ontología de Bloch, se debe reconocer lealmente que "El Ser-Que" pretende ponerse como la superación de un mero existencialismo y del puro esencialismo.

En cuanto el ser es entendido como "El Que", el ser es sólo la real PosibilidadUtopia de su Identidad con su esencia propia, con su "Lo-Que" (superación del esencialismo), en virtud de la actual y tópica dialéctica de su no-ser la existencia del ente, de no ser "lo que es ahi" (superación del existencialismo). 
dad, para pasar después a demostrar que se trata de una real oscuridad ontológica (quoad se), que es lo importante y relevante filosóficamente. Esta distinción, necesaria para evitar el psicologismo y salvar el valor ontológico del pensamiento blochiano, es fruto de una lectura comparada de los textos. A decir verdad, Bloch confunde frecuentemente estos dos niveles, prestando un flanco a fundamentales objeciones. Dé todos modos, según la exigencia de fondo de su ontología, el oscurecimiento del Logos en el $O n$ no significa que la oscuridad pueda ser removida por y en la A-Letheia teórica, tanto menos por la Orthotes; significa sólo que la oscuridad es ahora la misma calidad gnoseológica del Logos en sí y para sí, imputable a su calidad ontológica misma. El Logos es oscuridad y escondimiento, mera Lethe en el $O n$.

\subsection{El hecho de la oscuridad}

El hecho de la oscuridad quiere sólo poner de relieve la precedencia del ser respecto a la conciencia, es decir, el hecho de que la conciencia, para ser conciencia, debe primeramente ser conciencia y que el sujeto cognoscente para conocer debe primeramente existir como sujeto cognoscente. Como se ve, el inicio de Bloch es algo obvio. Y el hecho de la oscuridad del ser, así entendida, es algo innegable y de fácil aceptación. Un posible desacuerdo no puede suceder en este momento, sino sólo posteriormente, en las implicaciones ontológicas, gnoseológicas y metodológicas que Bloch cree encontrar dentro de la oscuridad del ser del ente para la conciencia.

Si ponemos bajo examen no sólo nuestra vida orgánica, sino nuestra misma vida psíquica consciente, se llega a la conclusión desconcertante de que la vida es algo densamente tenebroso y oscuro para sí misma; es decir, que el existir acontece de manera inconsciente, que el ser consciente es inconsciente. Todos nuestros actos, hasta los actos llamados conscientes, no son presentes y luminosos para sí mismos en el mismo momento de su acontecer como actos. Sólo cuando son ya actos o cuando ya han acontecido (etimológicamente, "acto" significa "lo ya hecho", lo sucedido), toman conciencia y no sin esfuerzo de sí mismos. Pero esto de que este acto aquí y ahora es y actúa, esto es totalmente ignoto para el actor y para el acto. Ni el actor ni el acto se ponen delante de sí mismos, en claro y preciso relieve, en el momento mismo que son y actúan. Para cualquier acto psíquico humano, ya sea el querer o el representar, es necesariamente oscuro el momento de su acontecer en el mismo momento en que acontece, en el momento de su querer y representar. Porque son o en virtud de su ser Ahora mismo, el querer quiere y el representar representa, pero no pueden ya querer y representar 
conscientemente el mismo darse ahora de su querer y representar. Porque quieren y representan, quieren y representan. Pero el "porque" y "esto que ahora mismo quieren y representan", esto no es ni querido ni representado. El "Que se vive", esto es, el que ahora yo pienso, quiero, leo, escribo, fumo, juego, en el instante que son o en su Ahora, constituyen precisamente mi vida y mi misma vida psíquica, pero, por esto mismo, no los revivo ni represento psíquicamente en la original e inmediata instantaneidad de su acontecimiento. "Son vividos, pero no revividos psíquicamente" [gelebt nicht erlebt], son mi "vida" misma pero no son "vivencia" [Leben, nicht Erlebnis]. En nosotros acontece el vivir, en fuerza del cual simultáneamente vivimos, sin que simultáneamente lo revivamos en la conciencia.

El viviente y lo que él vive ahora mismo, el vidente y su visión, el oyente y su audición, el inteligente y su acto de entendimiento, el volente y su acto de voluntad, no se colocan a su vez como objeto de visión, audición, conocimiento y voluntad: se substraen a la vivencia de la conciencia que acompaña cada acto humano objetivante. Los actos conscientes son conscientes en razón de ese su ser-Ahora conscientes, pero no pueden darse razón de esa razón de su ser conscientes, pues por ella son constituidos conscientes.

Si ahora hablamos más universalmente, con un discurso válido para cualquier actor y acto, se debe decir que el momento mismo en el cual el actor es, el momento en el cual el actor actúa, a saber, el Ahora, no cabe bajo la luz de la conciencia, es tenebrosamente oscuro para sí mismo. La conclusión inferida del hecho de la oscuridad del Ahora, conclusión en que se concentra toda la la ontología y metodología utópica de Ernst Bloch, es que lo existencial, lo vital no es lógico-contemplativo, sino motórico e intensivo. El que el ente es, el ser del ente y lo que significa últimamente el ser del ente, su origen profundo y su sentido último, todo esto se substrae a la experiencia del conocimiento y de la conciencia que lo acompaña. El ser del ente es ignoto y es una incógnita para el ente consciente. Obviamente la validez del conocimiento y la existencia de la conciencia no son negadas por Bloch: Sólo se declara el límite de su ámbito y alcance, a saber, sólo lo óntico-fenoménico pero no lo ontológico mismo, sólo "lo objetivo" o "lo que está-ahí-delante", pero no lo original y fundamental, no el ser mismo del objeto y el ser mismo de sí mismo como sujeto.

La conciencia, que acompaña cada acto humano intencional, acontece y vive por el acontecimiento puntual de cada uno de sus actos, pero no puede llegar al punto del acontecimiento mismo, ni logra descender hasta lo debajo que puso el acontecimiento, ni puede terminar en su ejercicio intencional al ser mismo de su conciencia. La conciencia en 
tanto sabe, con ese su saber característico que está incluido en el conocimiento objetivo y que es distinto de él, qué es su acto y que su acto es (su factual existencia y determinación, su "da-sein" y "so-sein"), sólo en cuanto su acto "anteriormente" acontece o está puesto ahora en ser $y$, por consiguiente, se le puede ofrecer. Pero la conciencia, por esto mismo; no puede saber nada acerca del acontecimiento original del conocimiento-conciencia, en virtud del cual es y es tal, pues esto es precisamente su mismo venir al ser y su acontecer como conocimiento-conciencia, es el presupuesto de su determinación y ejecución cognoscitiva. Por consiguiente, no sabe ahora por qué y qué es esá actual intensidad por la cual es, ignora por-qué y para-qué es. El conocimiento-conciencia sabe todo acerca de lo óntico y de lo fenoménico y no sabe nada acerca de lo ontológico. En conclusión, es negado al conocimiento y a su conciencia el acceso al ser en su originalidad e ipseidad. El Ser, aquí y ahora, no es obvio sino impervio para la razón consciente, es "la Oscuridad".

Es en este punto donde Bloch distingue perspicazmente entre "el Ahora" [das Jetzt] y "el Presente" [die Gegenwart]. El Ahora mismo del ente no es ese ahora que experimentamos. El Ahora no es ese ahora del cual tomamos conciencia, sino es el Ahora mismo del tomar conciencia. El Ahora no es "el instante que revivimos" o "el instante de la vivencia psiquica" [Erleben, Erlebnis], comúnmente llamado "el Presente", en el cual constatamos la existencia del ente (un estado anímico, una situación, un objeto). El Presente tiene sólo un alcance óntico y se mueve en la dimensión de los fenómenos, se refiere exclusivamente a "lo que le está-ahí-delante". El Presente, pues, no es sino la toma de conciencia del ente o de lo "ex-sistente" y, por tanto, presupone necesariamente que la conciencia y el ente ya sean o existan. Esto quiere afirmar que la visibilidad óntica del Presente tiene su condición de posibilidad en la oscuridad ontológica del Ahora, en la más total ignorancia u oscuridad del instante original y originante del Ser-Ahora del ente.

"El Ahora", en cambio a diferencia del "Presente", es el instante mismo en que el ente viene al ser y es el instante mismo de "la vida" [Leben], "el instante mismo que vivimos" [der gerade gelebte Augenblick] y por el que somos vivos. Este momento ontológico es necesariamente oscuro para la conciencia óntica o "Presente". "El Ser-Ahora" antecede o precede "el Presente". Y la precedencia necesaria del ser para la conciencia, la presuposición del ser por parte de la conciencia, muestra ya suficientemente el total carácter nocturno del ser del ente para la conciencia humana.

Esta situación totalmente oscura y vacía de inteligibilidad del ser para la conciencia del ente es el tema fundamental y capital de Bloch, incesantemente repetido a lo largo de sus obras, pero no siempre lógi- 
camente ordenado, por lo que mezcla planos psicológicos con planos ontológicos. Tema expresado con penetrante agudeza y con un estilo literario tan maravillosamente refinado como lacónico. He aquí algunos de los muchos textos:

Yo estoy en mí. El que yo camino y hablo, esto no está ahí. Sólo inmediatamente después puedo fijarlo delante de mí. Nosotros mismos, mientras vivimos, no nos vemos, nos escapamos a nosotros mismos. Por tanto, lo que aconteció ahí, en el momento que vivimos, lo que nosotros ahí propiamente éramos, no quiere recubrirse con lo que nosotros, reviviéndolo, podemos percibir de él. Pues, entonces, no es ya aquello que es y tanto menos aquello que se piensa que sea. ${ }^{10}$

Demasiado cerca. Nosotros somos. Pero, ¿quién es quien es? ¿y cuándo está él junto a lo que vive y en lo que vive? Nosotros no nos aprehendemos con frecuencia, si es que alguna vez nos aprehendemos. Demasiado inmediatamente. Nosotros somos siempre, pero no nos vemos. $\mathrm{Y}$ esto porque nos estamos muy cerca. Ni siquiera lo vivido por nosotros, precisamente por sernos tan cercano, es revivido en la conciencia. Lo vivido se pone ahí delante de nosotros, sólo si se ha alejado un poco.11

Que se vive, esto es precisamente lo que no se puede percibir. Esta pulsación inmediata es algo que palpita solitariamente. Actos como el querer y el representar y otros más no logran salir fuera de la inmediata oscuridad de su acontecimiento. Pero, en definitiva, lo más oscuro es el Ahora en el que vez por vez nos encontramos como seres perceptivos. El Ahora es el lugar donde se encuentra el fogón de la misma percepción y donde se encuentra como problema. Lo vivido en este mismo momento es lo que nos está más inmediatamente $\mathrm{y}$, por esto, lo que no puede ser de ningún modo experimentado. El ahora, además de ser vivido, es también revivido, sólo si y cuando haya pasado o cuando es esperado y mientras tanto que es esperado. Pero su inmediato ser ahí es algo que yace en la oscuridad del instante. Sólo lo que está ya por venir o lo que ha apenas pasado tiene la distancia que el rayo de la luz de la conciencia necesita para iluminarlo. El Que y el Ahora, el Instante en el que somos, hierve en sí mismo y no se experimenta a sí mismo. Por esto, el contenido correspondiente a lo vivido ahora mismo no es aprehendido conscientemente. ${ }^{12}$

10 Geist der Utopie, Suhrkamp Verlag, Frankfurt, 1964, p. 17.

11 Philosophische Aufsätze, p. 13.

12 Das Prinzip Hoffnung, Suhrkamp Verlag, Frankfurt, 1959, p. 334. 
Que se vive, esto no se puede percibir. El Que, que nos pone como vivientes, no se pone de relieve. Yace profundamente, muy abajo, allá donde se comienza a ser corporales. Se alude a este impulso, cuando se dice que el hombre no vive por vivir sino "porque' vive. Ninguno ha escogido este estado impulsivo, está con nosotros desde el momento en que somos y mientras somos. ${ }^{13}$

Lo vivido inmediatamente puede ser revivido psíquicamente sólo cuando pasa y se aleja, pero entonces ya no es igual a lo que se escondía en la inmediatez. En cuanto este inmediato Soy y Es no logra apoderarse de sí mismo, se encuentra aún en un punto ciego. Se debe decir además que la debilidad que el espíritu experimenta al relacionarse al Ahora experimentado (que comúnmente es llamado el Presente, pero que no se yergue ya tan cercana y rápidamente delante de nosotros), depende totalmente de la oscuridad del momento que se vive. $Y$ el ser-fundamento del existir, que aún no se posee totalmente, está ahí en la oscuridad... ${ }^{14}$

\subsection{La razón de la oscuridad}

2.2.1 La imposible toma de conciencia del Ser-Ahora a causa de su inmediatez o de su "cercania sin distancia" para con la conciencia y de su consiguiente imposible objetivación.

Afirmado el hecho de la actual incognoscibilidad del ahora del ser para la conciencia, es importante darse razón de este hecho. La razón por la cual el ser-Ahora (El que en este momento se es y se vive) es oscuro e impenetrable, puede ser de índole psicológica. Por ejemplo, la demasiada dispersión o la demasiada concentración de la conciencia, la extroversión sin reflexión, la luminosa y cautivante presencia de lo que se vive, el excesivo interés o la desmedida pasión del sujeto por la experiencia que ahora vive o por el objeto de su experiencia... etc.

Sin embargo, abandonadas estas razones psicológicas, que son contingentes y accidentales al acontecer del acto vital en el Ahora mismo de su acontecimiento, se descubre que la razón fundamental por la cual la conciencia está en la imposibilidad de captar el ser y su interioridad propia, es la falta por parte del ser-Ahora, de "la distancia" [der Abstand] requerida para su toma de conciencia. La razón de la oscuridad es " $l a$ cercanisima cercania" [die nächste Nähe] o "la cercania sin distancia" [die abstandslose Nähe] o "la inmanentisima inmanencia" [die inmanenteste Inmanenz] del ser para con la conciencia, la antecedente y si-

13 Ibid., p. 49.

14 Tübinger Einleitung in die Philosophie, p. 227 s. 
multánea inclusión del ser en la conciencia, la necesaria precedencia del "en-si" de la conciencia respecto al "para-si" de la conciencia. O expresado negativamente, la razón de la oscuridad del ser depende de su "noobjetividad" [unobjektiviert sein], de su "no-ser-fenómeno" [Nicht-Erscheinung-Sein], de su "no-ser-ahf" [Nicht-Da-Sein] para el conocimiento consciente. En suma, por encima de las razones psicológicas, imputables a la situación contingente de la conciencia empírica individual, la primera razón de peso es gnoseológica, imputable a la relación que guardan ser y saber.

Esto equivale ya a afirmar que el punto de partida de la ontología y su correspondiente método no pueden tener su lugar en la inmediata experiencia (interna o externa) del ser por parte de la conciencia, ni en la inmediata autoconciencia del ser de la conciencia. Para Bloch, la experiencia de la conciencia, en cuanto estructuralmente objetiva, se refiere necesariamente al objeto, pero carece de cualquier referencia al ser mismo, pues éste no es objeto de la conciencia del sujeto, sino es el ser o existir mismo de la conciencia del sujeto, ese su fundamento originante que, si se quiere intentar expresarlo con conceptos familiares pero aproximativos, puede ser formulado cuando menos como la existencia del sujeto (como esto que el sujeto es), pero de ningún modo como ser objeto para el sujeto y, tanto menos, como el objeto existente. En breve, el ser no es saber. Lo actual e intensivo no es eidético, el sujeto no es objeto. Se comienza, pues, a entrever que para Bloch el ser se revela no como objeto y esencia, sino como sujeto y existencia. Y expresado en su formulación lógica, "el ser es sujeto pero no es predicado", "S no es $P$ ". Y trayendo a la luz sus implicaciones metodológicas, se debe decir que la vía que puede conducir a la meta del ser no es la vía del "Lo-Que-Es", sino la de "El-Que-Es" y, por tanto, no es la de la conciencia-esencia sino la de la praxis-existencia. Bloch escribe: "el velo de la conciencia es contenido de la praxis [Schleier des Bewusstseins, Inhalt der Praxis].

El sujeto, pues, que por introspección inmediata o reflexiva quiere aprehender el ser, tiene que concluir, si su meditar es profundo y sin presupuestos, que el ser ahora mismo un sujeto que medita le deriva de eso que ahora mismo es un sujeto que medita, de eso que ahora es $y$, por tanto, su cavilar e introvertirse nunca podrán llegar a terminar en el ser. El ser no puede estar como objeto de contemplación (inmediata o reflexiva) para la contemplación, en cuanto es precisamente el fundamento originante y el mismo acontecer de la contemplación. Es evidente que la conciencia podría tomar conciencia del ser sólo en el instante en el cual la conciencia viene puesta en ser. Ahora bien, el serexistir de la conciencia no puede ser ya "objeto" de conciencia, ya que 
ello es en sí mismo el surgir y constituirse de la conciencia como tal. En efecto, no puede ser "objeto" lo que es en sí el fundamento de la existencia de la conciencia como "sujeto" que a su vez hace posible que la realidad sea objeto, es decir, hace posible el conocimiento óntico pero no ontológico. Sólo cuando el conocimiento consciente "es", es simultáneamente consciente de sí mismo, pero su original acontecimiento o "es", en virtud del cual es ahora consciente, es algo, por fuerza, incomprensible. El existir ahora mismo de la conciencia o el "en-si" de la conciencia no puede ser consciente, no es "para-si". Dentro y a partir de su "en-si" o a partir del hecho que "ahora la conciencia es", la conciencia toma conciencia de su objeto y de sí misma, pero entonces no es ya la toma de conciencia del ser original y originante de la conciencia, sino la toma de conciencia de la conciencia ya existente, de sí misma como una determinación existente. La conciencia no capta entonces lo que el ser es en sí de modo que la conciencia sea el "para-si" del ser, sino capta sólo que ella es y, por tanto, del ser capta sólo que es "eso de que se es": el Ser como Ser y existencia del ente. El darse de la conciencia como "acto" antecede (ontológica, no cronológicamente) o, como dice Bloch, es demasiado cercano e inmediato al darse de la conciencia como "intencionalidad". La intencionalidad de la conciencia supone, como su fundamento, su real actualidad o posición en la existencia. $O$ dicho aún con Bloch, lo real e intencional se recubren e interpenetran, "ocupan el mismo lugar". Es por esto que lo real, que es la misma actualidad básica de lo intencional, no puede dirigir la intención de la conciencia hacia sí misma, la priva del campo óptico requerido por ella para el aprehendimiento y la comprensión. Por esto, "lo más cercano es lo más lejano" [das Nächste ist sich derart am fernsten], lo más cercano ontológicamente es lo más lejano gnoseológicamente. El "en-si" de la conciencia no es y no puede reducirse inmediatamente a ser ya el "para-si" de la conciencia, sino requiere mediaciones. El sujeto, que por introspección o autoconciencia quiere aprehender el ser, tiene que concluir que la condición de posibilidad de que él pueda ponerse delante de sí mismo como un ahí objetivo de conocimiento se encuentra en su ser aqui y ahora y que, por consiguiente, ese su ser o estar o hallarse realmente aquí y ahora, que es lo que interesa al sujeto para poder descifrar la incógnita del ser o existir, esto no es a su vez un algo ahidelante, sino es eso por lo cual lo que está-ahí está y puede estar, eso que lo que está-ahí está ahí. El ser no está ahí para la conciencia, es sólo y sin duda el "es" del ahí, pero no lo-que-está-ahí. El ser "es" [es ist] pero "no se da" [es gibt nicht]. "Es su Ahí lo que precisamente no se da" [genau sein Da gibt es nicht]. En breve, y por ahora afirmando sólo con un significado gnoseológico, el Ser es "Ser-Que sin Ser-Ahi" [das 
Dass-Sein ohne Da-Sein], afirmación que posteriormente alcanzará un significado ontológico.

Bloch tiene ante sus ojos en este momento la imponente tradición del idealismo alemán y quiere ajustar cuentas con ella (en honor de la verdad, su confrontación es genérica y en puntos claves hasta rudimentaria), criticándole su presupuesto de la identidad absoluta entre ser y saber, asumida a nivel de "método" y de "sistema", y entendida como el necesarísimo punto de partida de toda ontología verdadera. A este planteo Bloch responde negativamente criticando la posibilidad de una inmediata "intuición intelectual" [intellektuelle Anschauung] del ser. La "oscuridad" significa, entonces, la no identidad entre ser y saber y ésta se fundamenta en la necesaria precedencia del ser a la conciencia, de la vida a la vivencia. Bloch da como obvia esta razón y, en vez de profundizarla y justificarla rigurosamente, ofrece sólo ejemplos y metáforas que ayuden a clarificarla. De todos modos, el corazón de la tesis de Bloch consiste en la negación de una inmediata identidad entre saber y ser, en razón de lo que llama la "demasiada cercanía" y, por ende, "la falta de distancia" entre el ser y la conciencia de ser. Por esto, "lo más cercano es lo más lejano" [das Nächste ist derart am Fernsten], lo más cercano ontológicamente es lo más lejano gnoseológicamente. De donde, sólo la conciencia que mire lo más lejos posible es la que puede mirar lo más cercano e inmediato: sólo la conciencia utópica es la conciencia ontológica. $\mathrm{O}$ con la bella expresión de Bloch, "se requiere el más potente telescopio, el de la perspicaz conciencia utópica, para poder penetrar en la más cercana cercanía". La conclusión es que ser y conciencia, esse et intellectus, lo real y lo racional, por estar demasiado juntos y cercanos, están demasiado separados y distantes. La demasiada inmediatez de ambos exige una mediación no sólo metodológica sino sistemática. Una mediación práctica e histórica, no sólo lógico-teórica.

Metafóricamente expresa Bloch sus tesis de la oscuridad, de la incapacidad ontológica de la conciencia teórica, con metáforas muy atinadas: "la zona del silencio" [Zone des Schweigens], donde el lenguaje estructurado a partir de lo mundano está obligado a callar, a permanecer sin palabras adecuadas respecto del ser; "el cuarto oscuro" [Schlafkammer], donde el sujeto revela las impresiones y los fenómenos en la más total oscuridad, donde revela el negativo (lo ontológico) positivamente (lo óntico), donde la oscuridad del ser pone la aparición del ente. Igualmente el Ahora puede ser comparado con "el punto ciego" [der blinde Fleck] de la retina, inhábil a la luz de los objetos y sin embargo el punto por el cual la retina es habilitada a captar la luz de los objetos; es decir, la oscuridad del ser pone lo óntico como fenómeno y lo psíquico como aprehensión y comprensión del fenómeno. 
Quien se encuentra en el Ahora vive particularmente unido e inmediatamente cercano al Ahora y, precisamente por esto, el Ahora es vivido. Pero, el viviente y lo vivido por el viviente, precisamente por ser tan cercanos, no se perciben, les falta la distancia necesaria para la toma de conciencia. Más aún, el Ahora puntual, en el que los vivientes están inmediatamente ubicados, es lo más oscuro. Y, dado que el Ahora es lo siempre incesante, su sombra se extiende a lo largo y por dentro de toda la vida. ${ }^{16}$

El hecho de que el hombre no perciba el Instante mientras éste acontece, sino sólo antes o después, esperándolo o recordándolo, tiene sin duda en la demasiada Inmediatez su fundamento primario y permanente. Esto no excluye que se den también otras condiciones adicionales que, dado el caso, refuercen la oscuridad del Instante... La oscuridad del preciso Instante en que se vive está, pues, diferenciada y reforzada por sombras psicológicas y sociales.

Sin embargo, lo primario es siempre ese cuarto oscuro del instante preciso que se vive, aun cuando se logre la relación más lúcida y poderosa con el Ahora. En efecto, su oscuridad coincide profundísimamente con la cercanía sin distancia de lo que en el Ahora está depositado. ${ }^{16}$

Ni el oyente del oír ni el oír, ni hasta lo inmediatamente oído pueden ser oídos. Todo esto cae dentro de la zona del silencio y está aún cubierto por el silencio. Se le puede también expresar con una imagen tomada de la fisiología y que parece ser bastante concerniente: así como la retina en el punto donde es penetrada por el nervio óptico es inhábil a la luz y tiene un punto ciego, así también el sujeto de experiencia se encuentra en la noche más oscura respecto a lo que él ha experimentado en su experiencia. Y así como el punto ciego no es la causa de ningún defecto constatable en el campo visivo... así también la oscuridad del momento preciso que se vive está y permanece normalmente escondida. La carencia de un estímulo óptico puede ser constatado sólo donde hay órganos nerviosos sensibles a la luz, los cuales faltan precisamente en el punto ciego. Por eso, ni siquiera se puede ser consciente del defecto nocturno de conciencia en el Ahora... Sólo indirectamente se puede declarar la existencia de ese punto ciego de la conciencia. ${ }^{1 ?}$

Poética y concisamente resume Bloch su punto de partida, ocasionado por la admiración problemática, con dos sentencias penetrantes: "El

I5 Philosophische Aufsätze, p. 74.

16 Ibid., p. $80 \mathrm{~s}$.

17 Ibid., p. 81 s. 
pabilo del cirio arde sin luz" [Die Kerze brennt am Doch dunkel]. "Al pie del faro no hay luz" [Am Fuss dess Leuchturms ist kein Licht]. La conclusión es que "Lo más cercano es lo más lejano", lo más cercano ontológicamente es lo más lejano gnoseológicamente. El ser es la actualidad íntima del ente y a la vez su escondimiento más remoto en el ente y para la conciencia del ente. "Soy" y, sin embargo, fuera de mi existencia presente, como el hecho de estar aquí caracterizado contingentemente de este modo, nada me es claro y sabido. Aquí y ahora mero On sin Logos, mera existencia sin tener la razón y el sentido de ella. La oscuridad ontológica no es una oscuridad que me circunda, ya que no proviene de entes carentes de luz (o sea, es posible y, sin embargo, no tiene un sentido decisivo y último, una verdad como orthotes, como "adecuación" al ente, como ciencia positiva o filosofía fenoménica o fenomenológica), sino una oscuridad que me permea desde adentro y que es mi ser, poniéndome como oscuridad aquí y ahora indescifrable y densamente impenetrable. "¡Cuán inquietante es todo y qué tremendamente extraño es ser!" O sea, la verdad hoy no es. Es posible, si realizada, que la verdad un día acontezca. La verdad hoy no es "A-Letheia", la "A-Letheia" es sólo posible como "Apocalipsis". La ontología es y permanece aquí y ahora problema-misterio para cualquier conocimiento contemplativo-panorámico y debe ser por esto la toma de conciencia del real problema y el intento práctico-utópico de solución. La "Parousía" ontológica no es ya la Revelación del Logos in principio o inmanente en el presente actual, sino acontecerá al final del tiempo mediante esa "hipótesis" que es el mundo (sujeto-objeto, hombre-naturaleza) llevada productivo-dialécticamente a "verificación" absoluta. "El velo de la conciencia es contenido de la praxis." Lo hoy misterioso contemplativamente es lo revelable prácticamente: la producción del Apocalipisis.

En conclusión, el Ser-Ahora, el existir, es tremendamente oscuro e impenetrable. Y la existencia misma, tan cercana e intima al existente, es precisamente ese fondo sin fondo al cual el pensamiento racional no logra descender y del cual no logra extraer nada. La existencia misma es lo irreducible a Idea de la conciencia, es aquello de lo cual la razón no puede darse razón. Esta raíz oscura y misteriosa para el pensamiento es el origen mismo del pensamiento, del pensamiento filosófico profundo. El saber como no saber nada acerca de su ser, es lo que pone originalmente la contradicción o la diferencia dentro del saber mismo: la conciencia objetiva como no objeto de conciencia, la conciencia como inconsciente. Esta contradicción o minus del pensamiento es precisamente lo que pone en movimiento (dialéctico) al pensamiento mismo como proceso de cuestión-solución-cuestión, y lo que constituye al saber más como un sujeto de la facultad intensiva y práctica, que como su- 
jeto de la contemplación pasiva del objeto. Esta contradicción es sobre todo lo que obliga al sujeto a desplazarse y rebasarse no contemplativa sino práctica y productivamente hacia el objeto, para extraer y traer a la luz del saber esa oscuridad de su saber. Esta contradicción obliga al saber a removerse como saber y a trasladarse hacia los entes, para obtener por el rodeo de la praxis objetiva su Identidad como saber, la Identidad de ser y saber. Sólo mediante la energía de la praxis (que es la coparticipación real y mutua del sujeto y del objeto) se rasga el "velo" eidético de la conciencia y se media y supera "la distancia" entre ser y saber, sujeto y objeto.

Conviene todavía profundizar acerca del porqué de tan gran oscuridad. ¿La Razón última responsable de la oscuridad se encuentra en la conciencia o en el ser mismo? ¿El fundamento de la actual imposibilidad de comprender lo que es el ser es reconducible a lo psicológico, y precisamente a la necesidad que la conciencia tiene de ser precedida por el ser para poder ser conciencia, o es reconducible al mismo fundamento ontológico, y precisamente a la necesidad que el ser aún tiene de realizarse idénticamente consigo mismo para poder ser objeto en-sí lógico y comprensible y sujeto que entiende comprensivamente su "objetividad"? ¿Toda esta oscuridad misteriosa y problemática del ser depende de una situación de hecho, de la razón limitada del hombre, de lo óntico-psíquico de la conciencia empírica que no puede elevarse al Logos ontológico o lo ontológico mismo es No-Logos, Lo-Que es sin Logos? ¿La oscuridad del ser depende de la conciencia que no puede necesariamente "objetivar" el ser o depende del ser mismo que carece de un contenido "objetivado" u "objetivable"? Este punto es decisivo. Si el ser es oscuro inmediatamente a la conciencia del ente, a causa de la situación misma de la conciencia respecto al del Ser, como Bloch afirma, pero no es oscuro en y para sí mismo, de manera que se pudiera alcanzar mediatamente su visión (no importa enunciar aquí todos los requisitos gnoseológicos y ontológicos de tal "mediación", ni importa aquí enunciar las variantes de tal mediación), entonces la opción blochiana por una oscuridad del ser en sí, basada en la imposibilidad de su conocimiento inmediato, comenzaría a zozobrar ya desde su arranque.

Si el ser es oscuro para la conciencia que, por referirse inmediatamente a lo óntico, eclipsa el ser (mero "Entendimiento"-"Verstand", "objectum materiale intellectus"), pero no es oscuro para la conciencia que se eleva mediato-inmediatamente a una pura "Razón"-"Vernunft" (con el Ser mismo como su objectum formale o a priori), entonces todo el agudo punto de partida de la filosofía de Bloch se derrumba como filosofía ontológica y se vuelve quizás sólo una buena y estimulante filosofía crítica de la tradición ontológica, una óptima fenomenologia de "las 
intenciones utópicas de la conciencia" (esperanza y desesperación, deseo y temor...), o bien sólo una "desideología" (una negación de la ideología en favor de la utopía), motivada por la enorme pasión que Bloch siente por un mundo en proceso hacia un futuro maravilloso y por un hombre como su factor o el hombre de la "esperanza militante".

El resultado, pues, de Bloch, a este punto, en firme contraposición a la Identidad entre Ser y Saber del Idealismo alemán, se centra en la Diferencia entre el "en-si" y el "para-si" del ser del ente, entre el ser y el saber de ser. Hay una Identidad entre ser y saber, en cuanto el saber "es" (a nivel de "en-si"), pero hay una No-Identidad entre ser y saber, en cuanto el saber ignora su "es" originante (a nivel de "para-si"). El punto de partida blochiano es el haber dado el predominio a la Diferencia sobre la Identidad. La Identidad está puesta dentro de la Diferencia y, por esto, Diferencia dialéctica. Por esto, el método de Bloch tiene también su punto de arranque en esa "No-Identidad de la Identidad y la NoIdentidad", invirtiendo así la proposición central de la dialéctica hegeliana. Bloch dará un paso más adelante, dando a su punto de partida no sólo una calidad "metodológica" (quoad nos; respecto al "para-si"), sino "sistemática" (quoad se; respecto al "en-si" y "para-si" del mismo ser del ente), una calidad no sólo "fenomenológica" sino "lógica". Una Lógica que, en virtud de la Diferencia, no puede ser sino "posible" y "utópica": "la Lógica del Apocalipsis" [die Logik der Apokalypsis]. Y a esta meta se puede llegar sólo por el camino-método de la Diferencia que exige, en fuerza de sí misma, una dialéctica materialista-histórica, un predominio de la praxis productora del Objeto por parte del Sujeto y no de la contemplación teórica del Objeto. En efecto, el no saber fundamental, en la medida que no sabe nada acerca del ser, es ya la remoción de la fundamentalidad del saber en favor de la fundamentalidad de la praxis. El no-saber es ya en sí la alusión al primado de la espontaneidad y energía de la existencia sobre lo dado eidéticamente o la esencia, de lo motórico sobre lo lógico, de la potencia sobre la forma. Sólo mediante la remoción, traslado y superación del saber teórico dentro de la praxis, se entra en la autenticidad fundamental del ser: el existir productivamente y no el dato esencial producido. Y sólo mediante esta remoción del saber en el hacer, el saber es copartícipe del ser y pone la real posibilidad o utopía de conquistarse como saber. Mediante la diferencia, "la oscuridad" o "la distancia", que el saber descubre entre saber y ser, sujeto y objeto, se vuelve "alborada" [Dämmerung] y "perspectiva" [Perspektive].

Ahora bien, el rango dado por Bloch a la Diferencia, por la que el no saber nada acerca del ser es lo primario y permanente en la existencia, parece ser que excluye no sólo la actualidad sino también la posibilidad 
de saber algo alguna vez acerca del ser: la posibilidad misma de la ontología en cuanto tal, utópica o no. ¿No zozobra ya, en fuerza de la diferencia, su proyecto ontológico como posible utópica identidad entre ser y saber? En efecto, ¿cómo se puede saber algo acerca de esa posibleutópica identidad del Ser, si del Ser no se sabe nada? ¿Qué cosa añade la invocación de la praxis respecto a la ignorancia del ser? Es importante, además, añadir, para entender totalmente cómo Bloch elabora su método y sistema, que Bloch se quiere poner como una "via media", un tercer camino entre la pura Identidad y la pura Diferencia. El idealismo pone como Prius absoluto la identidad entre ser y saber (el Saber) y como momento secundario o factual la no-identidad (el No-Saber), que además es únicamente un momento contingente y subordinado a la identidad (dialéctica o no) y está englobado dentro de ella. Bloch ve la dificultad del idealismo justamente a causa de esa "Aufgehobenheit" de la Diferencia dentro de la Identidad o de esa "Identidad de la Identidad y la No-Identidad", ya que en este caso no se conserva perfectamente ni se otorga cabalmente autenticidad a lo diferente, a la conciencia y existencia, empírica e histórica, con la inevitable consecuencia de un rígido monismo. Bloch, empero, ve igualmente el peligro de comenzar con la Diferencia como Prius y la Identidad como un momento secundario, fenoménico, factual, de modo que ésta se subordine y englobe dentro de aquélla. En este caso de la No-Identidad pura, la Identidad no es conservada y carece de una consistencia real, con la inevitable consecuencia de un pluralismo nihilista.

Bloch, entonces, quiere negar la presuposición de una absolutez del Prius, ya sea tanto como Identidad que como Diferencia, y trata de poner la Diferencia original como el impulso de un movimiento dialéctico que intrínsecamente apunta hacia la identidad posible o utópica, hacia la "pura identidad". Es la No-Identidad entre Ser y Saber, Sujeto y Objeto, Existencia y Esencia, lo que impulsa dentro de la misma No-Identidad (y con base en ella) hacia la Identidad entre Ser y Saber, Sujeto y Objeto-Predicado. La contradicción entre ser y conciencia, que es una contradicción nihilista si la conciencia no rebasa el encanto fetichista de la teoría objetiva y no disminuye su "distancia" contradictoria respecto del ser, es lo que obliga a la conciencia a removerse como conciencia teórica y a rebasarse en una praxis con mordente sobre el objeto y con producción del ser, a conquistarse por la mediación de la producción, como Saber, como Identidad entre ser y saber, entre sujeto y objeto.

La misma contradicción entre ser y conciencia es ya intrínsecamente el signo y el testimonio realísimo del ser como real posibilidad o real Utopia de la Identidad, el signo del ser como "lo aún-por-venir-al-ser", 
de la existencia del sujeto como algo objetivable o esencializable por el mismo dinamismo de la existencia del sujeto. He aquí "el principio Esperanza" [das Prinzip Hoffnung]: el ser esperado se funda en el mismo dinamismo del esperarlo o de la esperanza. La Identidad utópica entre sujeto y objeto se funda en su actual Diferencia o "distancia" que remueve, ateorética y prácticamente, la distancia. La Yarusía de la Forma se funda en la Potencia de la Materia. Y todo esto, según Bloch, está acuñado en la no-intuibilidad de la existencia por la conciencia esencializante, en la oscuridad del Ser-Ahora y del Instante. "Entenderse en la existencia" (el kierkegaardiano "Sich-in-Existenz-Verstehen") es el crear la esencia posible-utópica con la energía productiva de la existencia misma.

Ha llegado la hora de instaurar pura y totalmente el primado de la razón práctica, así como de referir la investigación de lo que el mundo es en verdad a la evidencia auténtica de la verdad, a la evidencia moral y mística, y de inaugurar la gnoseología y la metafísica de la esperanza iluminada. El mundo presente no es verdadero. El No-Saber es el único fundamento de la aparición del mundo. Y la pasión ardiente del hombre, como inquietud y ensueño, es la nave que zarpa hacia el otro mundo, hacia el saber definitivo, para atracar en el Ahora, en ese su contenido siempre pensado de un Aeternum Nunc Stans que aún no ha sucedido. ${ }^{18}$

El que el Ser no sepa nada acerca de sí mismo es justamente el impulso-fundamento [Trieb-Grund] para la aparición del mundo y, por esto mismo, es el tormento, la fuente y la característica cualitativa de su sustancia, de su materia, siempre preñada de utopía. ${ }^{19}$

2.2.2 La inmediatez como la subjetivación aún-no acontecida del Ser en si mismo y la objetivación aún-no acontecida del ser para si mismo en el Ahora.

En la diferencia gnoseológica que corre entre ser y saber, entre el en-sí y el para-sí de la conciencia existente, Bloch lee la diferencia ontológica entre ser y ente, que radicalmente significa la diferencia dentro del ser entre existencia y contenido-esencia, entre sujeto y objeto, "El Que" y "Lo Que". Diferencia que se media y pone como contradicción y así en Dialéctica y, por la dialéctica, en intencionalidad a la identidad o Identidad utópica. Esta articulación entre la diferencia gnoseológica y la

18 Ibid., p. $2 \mathrm{I} 5$.

19 Atheismus in Christentum, Suhrkamp Verlag, Frankfurt, 1968, p. 294. 
ontológica quiere decir fundamentalmente, según Bloch, que la diferencia-oscuridad es a la par, en un mismo movimiento, el inicio del sistema ontológico y el punto de partida del método.

Sin embargo, este tránsito de la diferencia gnoseológica a la ontológica no sucede mediante una "deducción" que parte de la premisa de la oscuridad del ser del ente para la conciencia existente, sino que se muestra ya, inmediatamente, en el acontecimiento mismo de tal oscuridad. No se pasa por silogismo de lo no-gnoseológico a lo no-ontológico. Lo nognoseológico, antes bien, es ya la declaración de lo no-ontológico o, más precisamente, "la oscuridad de lo ontológico mismo". En este sentido, la oscuridad es índice gnoseológico de la no-identidad acontecida y la no-identidad acontecida es el fundamento ontológico de la oscuridad. Con esto se puede notar muy bien el parentesco de Bloch, aunque invertido ("inversión materialista" remodulada blochianamente), con la tradición de la filosofía alemana. Así como el idealismo alemán, afirmando "la intuición intelectual" del ser, ponía inmediatamente no sólo una Identidad metodológica (como condición de posibilidad del método) sino sistemática entre Ser y Saber, así también Bloch, negando el darse inmediato de una tal intuición intelectual, pone inmediatamente no sólo una Diferencia metodológica sino sistemática entre Ser y Saber, Sujeto y Objeto.

La oscuridad, que no es sino la expresión de la inmediatez o de la no intuibilidad del ser con respecto a la conciencia, quiere significar precisamente que el ser "no se ha aún objetivado" [noch nicht objektiviert] ahi donde el ser es o donde hay ser: en el ente. Ahí donde el ser es, hay un objeto, el ente, que puede ser correctamente aprehendido y comprendido, pero, ahí, el ser en cuanto ser no se pone como objeto. El ser no se expone como objeto o no se expone en el objeto que él ahí pone. El ser pone el objeto sin exponerse objetivamente. El ser es, ahí donde es, más bien, un sujeto que es, el ente, pero, al no ponerse inmediatamente delante de sí mismo como objeto, se manifiesta ya únicamente como sujeto, como lo que ahí no se ha puesto ya o aún como objeto: "El que es" no es "Lo que es". Se es aquí y ahora y ahí, pero el Ser-Ahora no está ahora mismo ahí, delante de sí mismo, objetivamente.

El ser es la posición del objeto, pero sin que el carácter de posición o de estar puesto del objeto alcance en el mismo objeto su pura identidad o su exposición objetiva y, así, resulte ser la perfecta e inmutable posición del objeto. Esta posición real del objeto, que no es a su vez la pura y perfecta posición del objeto (el existir no es una posición firme que está decidida y definitivamente puesta fuera de cualquier coincidencia con el no-ser, fuera de la posibilidad, de la Nada y del devenir), significa la no posición del ser como objeto en el objeto por él realmen- 
te puesto, significa su No-Objetividad y, por consiguiente, la imposibilidad de una lectura comprensiva del ser: la inutilidad e imposibilidad de un método y sistema teórico. Lo que la oscuridad indica es justamente esta posición del objeto sin la exposición de la posición en el mismo objeto puesto. La oscuridad pone de relieve la precedencia del acontecimiento real sobre el acontecimiento de la conciencia, la precedencia de la posición del en-sí de la conciencia con respecto al para-sí de la toma de conciencia. La identidad simultánea entre la posición del objeto y la no-objetividad de la posición (la no autoconciencia de la posición) o, si se quiere, la Diferencia o No-Identidad entre el carácter de posición del objeto y la objetividad de la posición, es lo que la oscuridad de la posición revela claramente y lo que provoca la tan densa e impenetrable oscuridad del ser para la conciencia. Y esta no-objetividad de la existencia indica y origina la irreductibilidad de la existencia a lo eidético, de la ontología a teoría.

Ahora bien, para Bloch, afirmar que el ser, ahí donde es, en el ente, no se ha ahí objetivado, equivale ya a afirmar que, ahí donde el ser es, el ser no es ser; que, en lo que ahi es, el ser no es ya Lo-Que es pura y perfectamente; que ahí el ser es aún defectuoso respecto a la perfección de su contenido esencial propio y no se ha realizado aún como ser. Afirmar que el ser no se ha "objetivado" o, lo que es lo mismo, que la calidad de posición o existencia del objeto no se ha identificado con la objetividad o con el contenido del objeto, significa ya afirmar que, ahí donde hay ser o en el objeto que es, el ser no es ser, no es la perfecta e inmutable existencia de un contenido o el contenido existente inalterable en su existencia. Ahí, el ser es sólo la existencia o posición del objeto, pero no la puramente instantánea y simultánea (inconmovible y quieta) posición o existencia del objeto. Ahí el ser no tiene su esencia objetiva y su objeto esencial. Se es aquí y ahora (hic et nunc), pero no se es la firmeza y quietud del puro Ahora (nunc stans). No se ha objetivado el ser en sí y para sí. Sólo si el ser, ahí donde se es o hay ser, fuera Ser-Ahí y Ahora, fuera perfectamente lo que ahí es, identificándose sin residuos con el contenido ahí existente, podría acontecer la comprensibilidad del ser, porque, sólo entonces, instaurándose y exponiéndose el ser como ser o como lo que es puramente, el ser se expondría como objeto y así, dada su objetivación, pondría el real presupuesto para su comprensión. Por lo contrario, si el ser es oscuro, esto no puede sino indicar que el ser no es.

El ser no se pone como objeto en el objeto que el ser pone y, por tanto, no se pone como ser-Ser. El ser no se pone como ser en el objeto que el ser pone $y$, por tanto, no se pone como ser-Objeto. Hay una no objetividad de la posición o ser del objeto y, por tanto, la posición o el 
ser no es un purísimo ser o estar puesto. Hay un estar puesto o ser del objeto que no es un purísimo estar puesto o ser y, por tanto, la posición o el ser no es algo objetivo. La no-objetividad del ser, por tanto, quiere sugerir fundamentalmente la no-esencialidad del ser, su "no-Lo-Queidad" [Quidditas], su no-realización o no total cumplimiento como ser ahí donde es. En esto consiste la razón radical de la incomprensibilidad del ser. Y contraprueba es que, si el ser fuera ya Objeto o "Lo-Que-Es" puramente, se seguiría necesariamente que, ahí donde el ser es sujeto (ente), se captaría inmediata e instantáneamente como Lo-Que-Es, sería necesariamente Objeto para sí. Lo cual no sucede de ningún modo, pues entonces no acontecería la tan densa oscuridad del existir. La incomprensibilidad de lo ontológico depende últimamente del no acontecimiento de lo ontológico o del mismo ser como ser, como esencia objetiva. La oscuridad, en cuanto es la Diferencia que corre entre el ser-posición o el estar puesto ("en-si") y el ser-comprensión o el estar pro-puesto y ex-puesto ("para-si"), indica ya, irrefutablemente, la Diferencia que hay dentro del ser entre Sujeto y Objeto, entre El-Que-es y Lo-Que-es, entre Existencia y Esencia. E indica, aún más básica y sinónimamente, la diferencia entre ser y ente y, por ello, la negatividad misma del ser. Oscuridad significa que el ser es "Lo NO" [Das Nicht], "Lo-Que-No-es". Lo cual comporta y explica perfectamente esto que ahora el ser pase a ser un devenir inquieto y sometido aún a la Nada. Y esta negatividad del ser no puede ni debe ser demostrada argumentativamente, sino está ya acuñada en el acontecimiento mismo de la oscuridad.

El ser es y se revela, ahí donde es y se revela, sólo y exclusivamente como "El Que el ente es", "esto que en definitiva algo es" [dass überhaupt etwas ist] y no como "Lo-Que-es definitivamente" [das Uberhaupt]. El ser se declara sólo como la Existencia del ente y no como ya SerEsencia. El ser es fuerza y energía y no Logos o Eidos, el ser es lo singular y factual en movimiento y no lo Universal y Absoluto ya completo y entero. El ser es ahora un Sujeto-Quien-Que [Wer-Dass] no un Objeto o Lo-Que [was]. Lo cual, lógicamente expresado, da como principio: "Sujeto no es Predicado", "S no es P".

Lo que oscurece al ser, dando origen al problema ontológico, no es la Identidad primordial perdida, a la Hegel, al identificarse con la NoIdentidad: no es la existencia el oscurecimiento del ser-esencia. Lo que lo oscurece es la Diferencia primordial que está a la búsqueda de su identidad: el aún no ser esencia es el oscurecimiento de la existencia.

La oscuridad es, pues, el índice de esta no-identidad acontecida, de esta No-Objetivación del ser para-sí y, por tanto, no-subjetivación efectiva del ser en-sí. Y la oscuridad acontece justamente en virtud de esta No-Identidad del ser para consigo mismo. La oscuridad "revela" la ne- 
gatividad del ser y, más profundamente dicho, la negatividad del ser pone la oscuridad.

La oscuridad o no-objetividad del ser no significa ante todo, si bien la englobe y la fundamente, la no-onticidad del ser, es decir, que el ser no sea el ente ni sea como es el ente, que el ser no sea objeto como el ente es objeto y, por consiguiente, que el ser no pueda caer bajo esa mutua relación intencional de los entes, que da origen al conocimiento, ni sea así objeto de conocimiento óntico. El "Nicht" blochiano es más radical que el "Nichts" heideggeriano, que enseña a pensar el ser como fundamento del ente y no como ente. La oscuridad, resaltada por Bloch, rebasa esta afirmación y la recalifica más básicamente con la afirmación de que el ser no es ser, que el ser, ahí donde el ser es, en el ente, no es Lo-Que-es. La razón de la oscuridad o no-objetividad no depende de esa original y propia calidad del ser, la de no ser reducible al ente, por ser precisamente el ser del ente. Por tanto, no se puede decir que la razón de la oscuridad esté sólo en el conocimiento mismo o en el ente consciente que, por estructura, es inmediatamente objetivo u óntico. Tanto menos se puede decir que la comprensión de la originalidad irreductible del ser con respecto del ente, la aceptación de su necesaria no-onticidad, comporte la aceptación de una necesaria negatividad inmediata en la comprensión del ser, de una necesaria no inmediata intuibilidad del ser, lo cual inaugura ya la necesidad de una mediación teórica, en vez de excluirla. La razón de la oscuridad como No-objetividad del ser depende, por lo contrario, según Bloch, de ese No-ser del ser, de su inesencialidad, cuyo real signo y testimonio es la oscuridad. Y esta negatividad inmediata del ser debe ser asumida seriamente por el filósofo, de tal modo que cualquier mediación teórica sea innecesaria e imposible. En efecto, a una real no-identidad del ser se debe necesariamente responder con una real mediación del ser y no con una mediación teórica que, si se ciñe rigurosamente a su inicio negativo, no puede absolutamente mediar nada, al carecer de cualquier estímulo dialéctico teórico. Y esto quedó claro y definitivo en los resultados de Heidegger. La no-onticidad del ser no puede significar sino la misma no-ontologicidad del ser. Si el ser no es, ahí donde es o hay ser, en el ente, se sigue que el ser simplemente no es. Afirmar lo contrario, significaría ya el negar la consistencia y la autenticidad del "ahi" donde el ser es, del ser del ahí que es, del ente, y reducirlo a "apariencia" y últimamente a "nada", como en el caso del Idealismo, de las metafísicas de la transcendencia y de las ontologías fundamentalistas.

Si la conciencia no puede captar simultáneamente el ser, esto depende justamente de que el ser es sólo el "origen" o "fundamento" [Ursprung, Dass-Grund] de la existencia del ente y no es "Lo-Que" se ha puesto 
absolutamente en el ente, no es "contenido" [Inhalt] en el ente, ni el contenido del ente existente. Sin embargo, esto de que el ser sea, en el ente, origen-sujeto y no contenido-objeto, no debe ser entendido como si esto abriera ya y exigiera una ulterior etapa de la reflexión teórica para determinar lo que el ser es en sí y para sí. Bloch, aunque acepte esta ontología fundamental no esencialista, se adentra más radicalmente y pone la afirmación de que esto depende únicamente del hecho que el ser, ahí donde es, es sólo existencia-sujeto y no esencia-objeto, es No en-sí y No para-si. El ser "no se ha aún desplegado, como un contenido manifiesto, dentro del tiempo y del proceso" [noch nicht selber in die Zeit und den Prozess als Inhaltlich manifestiert entfaltet hat]. Y esto prohibe cualquier aventurarse teórico, deductivo o reductivo, a encontrar una Identidad más allá de esta su no-posición o negatividad. Al límite, el ser como origen significa " $u$ origen aún no originado" [der Ursprung ist selbst noch nicht entsprungen]. El Ser-Ahora no es sino esto que algo aquí y ahora es, pero de ninguna manera Lo-Que es Ser-Ahora, un objeto identificado con el Ahora inmóvil y así puesto de una vez para siempre. Y es sólo por esto, porque el Ser-Ahora no se ha aún puesto objetivamente en sí, en su esencia propia, que el Ser-Ahora no se ha "pro-puesto" o no se ha aún objetivado; y esta no-proposición del ser es la revelación de su no-posición.

Por más sencillo y apresurado que esto pueda aparecer ontológicamente, no se encuentra en Bloch otro argumento. $Y$, como de costumbre, Bloch pasa a expresar la densidad metodológica y sistemática de su punto de partida con fórmulas de una potente economía conceptual. Ser como No-Ser-Objeto significa que el Ser es "No-Ser-Ahi [Nicht-Da-Sein]" y esto debe ser entendido primordialmente no tanto, si bien lo incluya, como "no-ser-ente", en el caso que se dé al ente el nombre de "ser-ahi" [Da-Sein], sino debe ser entendido principal y únicamente como "no-ser" del ser, ahi donde el ser es: si el ser no es, no es tampoco ente. Ser es "no-revelarse", "no-ser-fenómeno" [Nicht-Erscheinung-Sein, Nicht-Offenbar-sein], entendido no sólo como su no aparecer inmediatamente a la conciencia del ente, sino como su no aparecer simplemente ahí donde realmente aparece: su no posición y exposición objetiva en la posición objetiva. EI Ser-Ahora del ente o "el Instante" (sólo la instantaneidad simultánea y quieta es el modo de ser que compete al ser) es "lo NoAhi del Instante" [das Nicht-Da von Augenblick] o "el Instante como No-Ser-Ahi" [Das Augenblick als Nicht-Da-Sein]. En este sentido gnoseológico y ontológico debe ser entendido que el ser "no ha aún acontecido", "no se ha aún extraido, resuelto, puesto" [noch nicht geschehen, unherausgebracht, ungelöst, nirgends gestellt]. En este sentido, el Ser es "el Ahora mismo del existir" [das Jetzt des Existere] como "No-existir", 
"Aün-No-existir" [Nicht-Existiere, Noch-Nicht-Existere] "dentro del mismo existir", dentro del núcleo del existir [im Kern des Existierens].

En este punto, la conclusión es que la no-objetividad $\mathrm{y}$, consiguientemente, la No-intuibilidad del ser implica no sólo la imposibilidad de comprender el ser a partir estrictamente del ente (reservándose ulteriormente otra vía no óntica de acceso al ser), sino implica también y ante todo la total imposibilidad de comprender el ser mismo, pues el ser, ahí donde es, es sólo el ser del ente ("esto que el ente existe ahora mismo") y no el Ser puro, un Lo-Que es firme y perfecto en el ser. El No-Ahí, la no-objetividad y no-revelación del ser del ente, bloquea cualquier vía de comprensión ontológica por medio de la teoría. La oscuridad no depende de la conciencia del ente sino del ser mismo. La imposible toma de conciencia del ser a partir del ente no alude ya a su remoción y a su superación por otro posible camino, sino anuncia y muestra la imposibilidad de cualquier camino metódico que comience y se desarrolle sólo y exclusivamente como teoría. No se trata, ante todo, de una superficial no-objetividad del ser para la conciencia del ente; se trata, más bien, de una profunda no-objetividad del ser en sí mismo y para consigo mismo, que lógicamente incluye esa su primera o superficial no-objetividad. En fin de cuentas, no tiene sentido, para Bloch, el distinguir entre estas dos no-objetividades, en cuanto la primera no es sino el aparecer de la segunda y la segunda es la razón de la primera. El que el ser esté oculto al ente consciente significa últimamente que el ser está oculto a sí mismo.

Lo que aparece como oscuro puede frecuentemente ser un falso gris o un falso negro. El problema, sin embargo, desaparece apenas uno se acerca a lo que aparece, porque tal oscuridad no estaba puesta en la calidad propia de la cosa. En cambio, la oscuridad del Ahora $y$ de su Quien se espesa, precisamente cuando uno se le acerca. Lo cual declara que aquí se trata de una oscuridad de la cosa en sí misma y del enigma propio de la cercanía misma. ${ }^{20}$

El Que del Soy y Es, meramente vacío e inmediato, esta $X$ que impulsa y pone todo impulso y toda extraposición, este fogón ardiente de todo tender en el existir y que es lo más oscuro; Aquí, en este punto, se encuentra el proto-impulso de todo comienzo que nos está permanentemente cercano y cercanísimo y que se encuentra en la oscuridad del instante en que se vive por la precisa razón que el ser no se ha aún objetivado en sí y para sí en ningún lugar y no ha aún aparecido en la historia. ${ }^{21}$

20 Tübinger Einleitung in die Philosophie, p. 273.

21 Ibid., p. 258. 
Por esta pulsación se experimenta el instante psíquico en el latir de su Ahora, en su irrupción hacia adelante y hasta en el carácter transitivo de todos los instantes. De todos modos, en esta inmediatez, no se pone de relieve sino este pulsar y la toma de conciencia no se extiende más allá de un mero sentir e indicar como oscuro el instante que se vive. $\mathrm{Y}$ con esto aparece lo más decisivo, lo que fundamentalmente hace que el problema hasta ahora afrontado supere la mera psicología: la oscuridad del momento que se vive es una imagen de la oscuridad del instante real. Es decir, es una imagen de ese No-Tenerse que caracteriza el elemento intensivo del tiempo, el cual no ha aún expuesto manifiestamente su contenido en el tiempo y en el proceso. Por tanto no es lo más lejano sino lo más cercano lo que es plenamente oscuro, y es completamente oscuro porque es lo más cercano y lo más inmanente. En esta cercania está escondida la maraña del enigma de la existencia. La vida del Ahora, lo propiamente intensivo, no se ha traído fuera de sí mismo y puesto delante de sí mismo, de modo que sea lo visto, lo patente y extraído para sí. Es por esto que el Ahora intensivo no es mínimamente un Ser-ahí [Da-Sein] y, tanto menos, un Sermanifiesto [Offenbar-Sein].

El Ahora del existir que todo impulsa y dentro del cual todo impulsa, es lo más imperceptible que se pueda dar; él impulsa permaneciendo todavía por debajo del mundo; él es lo que está en estado de realización y lo que no se ha realizado; él no es sino un momento oscuro de sí mismo. ${ }^{22}$

El Que, que impulsa en el Ahora, no es. Puesto que se puede hablar de él, el No no es o no es ya un No propiamente dicho... El No es el concepto que expresa ese punto cero del Tener que se encuentra en nosotros, pero que es ya el No-Tener... Sólo en la más total oscuridad se puede tomar conciencia de este bullir e impulsar, de esto que se halla en sí como No. Para nuestra conciencia eso es la más densa oscuridad del aquí y ahora y, con mayor razón, del ahí, que evidentemente no es de ningún modo un ahora, aquí y, tanto menos, un ahí que se tiene a disposición. El No es precisamente lo No-ahí.

Es decir, el No en su inmediato hallarse en sí es el ahí más fugaz que siempre se escapa y que no tiene absolutamente un ser-ahí que pueda ser retenido fuera de sí. Así como el No es un No impropio, así también el No 'se da' impropiamente, precisamente no se da su ahí. En efecto, si todo hallarse es el hallarse de un Quien con su Lo-Que, en el No como No-Tener no ha acontecido el Quien delante del cual algo pueda darse y ningún Lo-Que que 
se dé. El Que vacío, que es el No, esto de que en suma algo es, no se pone de relieve por sobre el Es del mero inmediato Soy. ${ }^{23}$

El factor subjetivo del darse del ente o ser-ahí no está aún ahí, no está como predicado, no está objetivado ni realizado. $\mathrm{Y}$ esto se pone de manifiesto en la oscuridad del momento que se vive. ${ }^{24}$

Por lo contrario, la situación del Ahora es, siempre y en todo lugar, el No-Ahí. Hasta el mismo Aquí de este No-Ahí representa la Zona de Silencio, ahi mismo donde se toca la música. Por consiguiente, no sólo el existir sino sobre todo el mismo sujeto del existir está en incógnito; es decir, tanto el que impulsa el existir como lo que es el contenido del existir son una incógnita. El pleno Carpe diem sería decisivo sólo en el caso que la cercanía, tan difícil de ser experimentada de manera inmediata, lograra que la actualidad del existir y de su contorno espacio-temporal no fueran ya opacos y difíciles. De todos modos los instantes laten silenciosa e invisiblemente. Su presente está en el mejor de los casos en la antesala de esa su presencia que aún no ha llegado a ser, aún no consciente. ${ }^{25}$

El concepto exacto de una cosa en sí -aprehendido y corregido materialísticamente- significa el En-sí como la aún permanente Oscuridad y el aún permanente enraizamiento del mismo núcleo de la materia. El En-si es, pues, el gigantesco Correlativo cósmico de la oscuridad del momento vivido. Todas las formas organizadas de la materia son, según esto, determinaciones crecientes que experimentalmente manifiestan esa $X$ material o esa $X$ en la materia. Esta X, por tanto, no puede ser entendida como si fuera sólo un enigma para el hombre, mientras en sí, más allá de la razón necesariamente limitada del hombre, estaría ya acabada y resuelta. ${ }^{26}$

Por consiguiente, quién y qué cosa sea el ser, cuál su itinerario y cuál término él tenga, cuáles futuras determinaciones nos prepare y, por tanto, qué cosa últimamente se pueda esperar del ser, cuál sea su sentido y valor, aquí ahora todo esto nos es ignoto, todo esto es incógnito para la "gnosis" contemplativa. La existencia, ligada al momento incognoscible de su ahora original y originario, no "ve" otra cosa que la multiplicidad, limitación y contingencia de los entes; no "ve" otra cosa que su dato bruto, su estar ahí arrojada, perdida y zarandeada en la

23 Tübinger Einleitung in die Philosophie, p. 243.

24 Das Prinzip Hoffnung, p. 349.

25 Ibid., p. 343.

26 Philosophische Aufsätze, p. 158. 
historia sin determinaciones precisas y con determinaciones contradictorias, sin rumbo unívoco, sin poder ser cierta que lo que le está adelante sea Todo o Nada, sea Vida o Muerte. O dicho más precisamente, si no se rompe con la contemplación, "viendo" que lo que le está adelante es sólo Nada y Muerte. Sin poder estar cierta que la existencia histórica llegue a ser Ser y que lo thoy todavía precario y funesto pueda terminar en cumplimiento y valor. Por consiguiente, si el ser es sólo contemplado (teoría sin praxis) y si el ser-No no trae consigo la dialéctica del No, que legitima y orienta la praxis creadora, entonces no se puede ni se debe afirmar ni augurar realmente nada de valor e inteligibilidad. Antes bien, es permitido y obligatorio afirmar la indeterminación, el absurdo, la nada del ser. Esta ontología teórica (fenomenológica) negativa sin dialéctica práctica de lo negativo ha sido llevada coherentemente hasta sus últimas conclusiones por el existencialismo alemán y francés de la postguerra.

La novedad ontológica de Bloch consiste, entonces, en reconocer profundamente la oscuridad gnoseológica y axiológica del ser, puesta su oscuridad ontológica. $Y$ en asegurar que por la praxis-teoria, por la fuerza de la esperanza militante-dialéctico-utópica (se fundamenta ontológicamente en la autorremoción por parte del ser de su negatividad y, por consiguiente, en la apertura positiva de identidad que la autorremoción del No inaugura), se puede remover la factual inmediatez o alienación del ser, se puede potenciar Iuminosamente su apertura y vislumbrar "la estrella" de la identidad y adecuación plena entre ser y esencia, que está depositada como "posible" en el ser del ente.

La oscuridad del momento en que se es, la no-objetividad del ser del ente, remueve ya la validez de cualquier método ontológico exclusivamente teórico-intuitivo. El Ser-Que sin La-Que objetivo se substrae a la estructura necesaria de todo conocimiento, con la seria consecuencia de un actual agnosticismo ontológico, mientras se permanezca cerradamente en la "gnosis" como instrumento ontológico o mientras se sea prisionero de un entendimiento de la filosofía como "sofía" en lugar de "filia": en lugar de la vitalidad, la pasión, la intensidad afectiva, la acción, la razón práctica. El carácter nocturno del ser del ente, que constituye el momento del inicio blochiano, es igualmente el momento de la despedida de la "razón pura", del conocimiento como método adecuado al ser, sin importar aquí la variante del método.

La presuposición teórica del método ontológico es removida de golpe por la no-identidad y la no-objetividad del ser. La inmediatez del ser no es de ninguna manera eidética-intuitiva, sino existencial-intensiva, es la de una dinámica de pulsión y propulsión en razón de esa misma noidentidad, no-objetividad. A esta inmediatez corresponde en el sujeto 
consciente la praxis, la praxis que por esa misma negatividad ontológica se orienta y apunta a la identidad y a la objetividad esencial y que para su realización se pone en movimiento de des-trucción y construcción del mundo. La praxis, la praxis dialéctica y utópica, la "esperanza militante", que trabaja en los fenómenos del mundo predado, resulta ser en Bloch la inmediatez-mediación de la teoría, de la lógica: de la praxis a la teoría, de la fenomenología a la lógica, de la negatividad topográfica a la utopía de la identidad positiva. La ontología, en sentido estricto, se recorta sólo como utópica, como fundamentalmente posible, presentándose hoy sin logos propio, como pura onto-génesis en acción. Al escenario cósmico y griego de "fenomenon" y "logos" se sustituye la perspectiva histórica judía de "eón" y "ésjaton". 